\title{
Effective Tutorial Ontology Modeling on Organic Rice Farming for Non-Science \& Technology Educated Farmers Using Knowledge Engineering
}

\author{
Jirawit Yanchinda ${ }^{1}$, Nopasit Chakpitak ${ }^{2} \&$ Pitipong Yodmongkol $^{1}$ \\ ${ }^{1}$ College of Arts, Media and Technology, Chiang Mai University, Chiang Mai, Thailand \\ ${ }^{2}$ International College, Chiang Mai University, Chiang Mai, Thailand \\ Correspondence: Jirawit Yanchinda, College of Arts, Media and Technology, Chiang Mai University, Chiang Mai, \\ Thailand. E-mail: jirawit.y@gmail.com
}

\author{
Received: February 24, 2015 Accepted: March 31, 2015 Online Published: August 26, 2015 \\ doi:10.5539/ies.v8n9p46 \\ URL: http://dx.doi.org/10.5539/ies.v8n9p46
}

\begin{abstract}
Knowledge of the appropriate technologies for sustainable development projects has encouraged grass roots development, which has in turn promoted sustainable and successful community development, which a requirement is to share and reuse this knowledge effectively. This research aims to propose a tutorial ontology effectiveness modeling on organic rice farming as an appropriate technology based on sustainable development projects for non-science and technology educated farmers using knowledge engineering approach, using Phrao District in Chiang Mai Province, Thailand as a case study. The effective tutorial ontology model focuses on social science and technology ontologies based on Thai's curriculum of lower secondary school which provides biology, chemistry, math and physics concepts in order to effectively represent knowledge of the organic rice farming. The additional social science ontology knowledge developed in this research provides such a support to vocational learning and used by rural community in the case study to effectively navigate and utilize the appropriate technological knowledge of the sustainable development project knowledge to enhance their communities. The effectiveness of tutorial social science ontology in learning process was measured by counting and validating the average throughput of organic rice farming domain knowledge in learning process in terms of practicing domain knowledge, appropriate domain knowledge with their community and acquiring knowledge by themselves in both control and experimental groups. This study concludes by emphasizing the benefits of effective tutorial ontology modeling on organic rice farming for supporting knowledge transfer technique for non-science and technology educated farmers using knowledge engineering in the community of the case study to enhance their vocational lifelong learning. Ultimately, the tutorial ontology modeling in appropriate technology provides a knowledge transfer for non-science and technology educated farmers effectively.
\end{abstract}

Keywords: appropriate technological knowledge, effective ontology, basic education, knowledge engineering, organic rice

\section{Introduction}

There are more than 4,000 sustainable development projects in Thailand, which involve appropriate technologies. The knowledge and practical experience from these projects which have a lot of expert's specification of conceptualizations are implemented in different areas of Thailand to promote rural development. The objectives of the sustainable development projects focus on self-sufficiency and environmentally-friendly farming. Knowledge of appropriate technology gained from the projects can be divided into six dimensions: land, water, forestry, agriculture, environment and alternative energy. The sustainable development projects create substantial amounts of valuable knowledge and individual practical experience which is crucial in strengthening communities. This appropriate technology can be applied to the various social landscapes of Thailand that have been used to increase agricultural output and in turn reduce poverty for rural communities. The knowledge of appropriate technology from the sustainable development projects has encouraged grass roots development, which has in turn promoted sustainable and successful community development. Traditionally, knowledge from the sustainable development projects has been utilized in a piecemeal way at rural geographic scales. This has led to duplication in effort and the full potential of project knowledge not being realized. 
The finding of appropriate technology knowledge transfer is rural farmers in Thailand who have not enough of basic education and science technology knowledge to understand and apply appropriate technological knowledge or expert's jargons for solving their rural community problems successfully. According to Thai education system provides 9 years: Pratom 6 of compulsory education, with 12 years: Mattayom 3 of free basic education guaranteed and set by the 1999 National Education Act. In 2003, compulsory education was extended to 9 years, with all students expected to complete with 15 years: Mattayom 6 (Ministry of Education, Thailand, 2008).Most of rural people in Thailand had education at elementary education level which are elementary school (Pratom 4-Pratom6) 92.58\%, lower secondary school (Muttayom 1-3) 46.82\% and upper secondary school (Muttayom 4-6) $25.29 \%$ (Office of the Permanent Secretary, Ministry of Education, 1992). Moreover, it can be seen from Office of the Permanent Secretary, Ministry of Education (2013) that most rural people at $91.36 \%$ in Thailand complete elementary education level more than other levels. The findings highlight a lack of specification of conceptualization understanding in the basic education level of rural community people in Thailand being unsuccessfully transferred appropriate technological knowledge which is maintained in the sustainable development projects. The social science and technology ontology in appropriate technological knowledge should be the keystone of sustainable development projects, which knowledge workers need to understand and solve real world problems. The result from the analysis of this research is that this lack of understanding of specification of conceptualization in appropriate technological knowledge should be addressed via a knowledge management solution.

The requirement to remember and understand expert's specification of conceptualization means a method is needed to transfer appropriate technological knowledge from multiple sustainable development projects via additional social science ontology knowledge as knowledge representation. Ultimately, appropriate technological knowledge can be shared and reused in order to solve rural community problems. Furthermore, rural communities can learn from collaborative and expert experience to create new solutions to problems. Accordingly, it is necessary to manage appropriate technological knowledge and an additional ontology is needed to extend this appropriate technological knowledge to other social landscapes across Thailand.

This paper proposes an effective tutorial scientific ontological based-knowledge with the objective of using a knowledge engineering approach to provide domain knowledge to support an appropriate technological knowledge for non-science and technology educated farmers in order to close gap between expert and organic farmers. This study is focusing on the organic rice farming particularly useful in rural areas and communities, as appropriate technology and using Phrao District, Chiang Mai Province, Thailand as a case study where most people had an education at basic education level. This research proposes additional ontologies of the organic rice as an appropriate technology by extracting key scientific concept from the biology, chemistry, physics and mathematics concepts as additional ontological knowledge. These four social scientific concepts relate to the basic education in the lower secondary school of Thai's curriculum and in parallel four formal social science and technology ontological categories are developed using CommonKADS. The biology, chemistry, physics and mathematics, scientific concepts, as well as the corresponding ontological domains, are explained in more detail in the methodology section of this paper. Before considering the social scientific ontological development in this research, it is necessary to outline and describe further what is meant by the term appropriate technological knowledge, particularly as it applies to the sustainable development projects.

\section{Literature Review}

\subsection{Appropriate Technology}

The appropriate technology common definition is a technology that is designed to solve social, environmental, cultural, economic and community situation problems around the world to sustain natural resources. The appropriate technology from sustainable development projects is implemented in different areas in many countries, to promote rural development (CSIR Built Environment Unit, 2008) The objectives of the sustainable development projects in Thailand focus on self-sufficiency and environmentally-friendly farming. The Knowledge gained from the projects can be divided into six dimensions: land, water, forestry, agriculture, environment and alternative energy. The sustainable development projects create substantial amounts of valuable appropriate technology and individual practical experience, which is crucial in strengthening communities (Ruanglertboon, 2003). An appropriate technology should be effective to practice and easy to maintain for many people. Moreover, an appropriate technology must be affordable and have a wide impact. This research focuses on organic rice farming as an appropriate technology to develop effective social science ontologies and transfer vocational knowledge to non-science and technology educated farmers in Phrao farmer's community in Thailand as a case study. 


\subsection{Ontology}

Recently, ontology has been used in a wide variety of research (e.g. Anumba, Issa, Pan, \& Mutis, 2008; Chou, Vassarand, \& Lin, 2008; Saito, Umemoto, \& Ikeda, 2007). Ontology is a specification of conceptualization to share common language or vocabulary which describes how things are organized in a particular domain and provides a shared common understanding of the relationship between people and computer (Akehurst, Rueda-Armengot, Lopez, \& Marques, 2011). Additionally, ontology eliminates the problems of conflicting meanings and terms during content retrieval (Isotani \& Mizoguchi, 2008). The role of ontology is to promote the reuse of knowledge structures in the form of ontology libraries. The main objective of an ontological library is the description of knowledge conceptualization related to large amounts of domain knowledge (Gil \& Martin-Bautista, 2012). This study develops social science ontologies of knowledge gained from the organic rice farming knowledge as a sustainable development project for non-science and technology educated farmers in Phrao District, Chiang Mai Province of Thailand as a case study. Ontological knowledge could be more useful and effective for farmers to learn from and apply to develop their communities. In this context, social science ontology is used to provide benefits, by training, sharing and reusing appropriate technological knowledge of the organic rice farming among academic officers, practitioners and farmers. This effective tutorial ontology could improve management performance in multiple sustainable development projects. The methodology in this research utilized ontology-based knowledge to apply and learn appropriate technological knowledge from the organic rice farming.

\subsection{Knowledge Engineering}

The knowledge of appropriate technology in this study which relies on expert experience is based on social scientific domain knowledge. Knowledge engineering is a means of mining and eliciting and knowledge from experts and can be seen as encompassing methods and techniques for knowledge acquisition, modeling, representation and usage (Uschold \& Gruninger, 1996). Many knowledge engineering methodologies have been developed over the years (e.g., CommonKADS (Uschold \& Gruninger, 1996, Protégé et al., Wielinga, 2000), MIKE (Angele, Fensel, Landes, \& Studer, 1998) and MOKA (Gennari et al., 2003)). This research focuses on CommonKADS to capture knowledge which is one of the most widely used knowledge engineering methodologies. The CommonKADS model has a variety of components such as the organization model, task model, agent model, knowledge model, communication model and design model. This research focuses on the knowledge model to structure the organic rice farming knowledge based on science and technology based framework derived from problem consideration, conceptualization, reasoning and implementation of a solution. Organic rice farming knowledge will be model based on each of the science and technology based method frameworks by CommonKADS in order to acquire scientific and technology knowledge for problem solving for organic rice farming case study. The scientific and science and technology knowledge were modeled into four corresponding parts; task knowledge, inference knowledge domain knowledge and ontology knowledge. The four main parts are linked to task knowledge, which describes the knowledge-intensive tasks of the organic rice farming; inference knowledge, which describes using knowledge to carry out the reasoning process; domain knowledge, which refers to knowledge of human experts based on their experiences; and ontology knowledge, which describes specification of conceptualization of organic rice farming experts.

\section{Research Methodology}

This study developed additional social science ontologies from the organic rice farming knowledge as an appropriate technology to transfer knowledge to rural non-science and technology educated farmers of Phrao District, Chiang Mai Province, Thailand as a research case study. The vocational learning process was experimented with Bloom's taxonomy framework to evaluate additional ontologies and vocational life-long learning of case study as shown in Figure 1. 


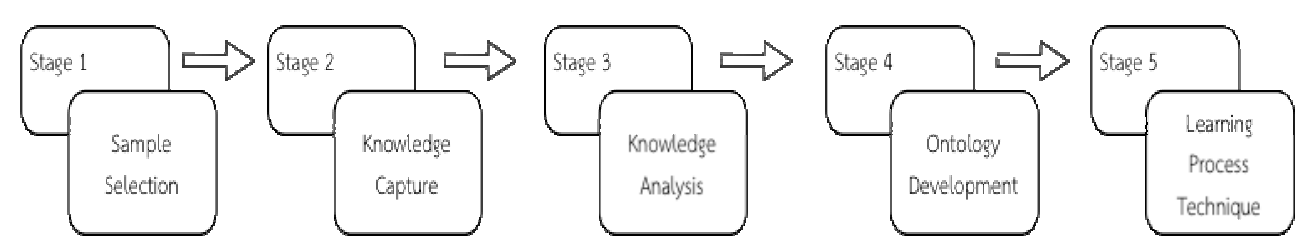

Figure 1. Research methodology

\subsection{Sample Selection: Stage 1}

This stage will involve the deciding upon, and then reviewing existing knowledge from a sustainable development project and an organic rice farming knowledge as an appropriate technology. A suitable sustainable development project will be identified to develop additional ontologies solution for appropriate technology. It is envisaged that Phrao District, Chiang Mai Province will be selected as an appropriate technology case study. The requirement knowledge to renew case study community will be validated by non-structure interview and vocational organic rice planting knowledge test from stakeholders and bio data analysis of case study. This research focuses on adaptive organic rice farmer to be a study sample to prove learning skill from additional ontologies, which was developed. The samples of the case study were divided into a control group and experimental group in order to test the effectiveness of additional social science ontology of appropriate technology.

\subsection{Knowledge Capture Using CommonKADS: Stage 2}

This study focuses on a social scientific ontology (biology, physics, chemistry and mathematic concepts) to enable tutor and reuse of organic farming knowledge derived from the sustainable development projects based on an appropriate technology. Organic rice knowledge as an appropriate technology can subsequently be validated, tested and disseminated via social science ontology for farmers in Phrao District, Chiang Mai Province as knowledge workers, particularly in rural areas of Thailand and with a particular methodological emphasis on the use of CommonKADS.

\subsection{Knowledge Analysis: Stage 3}

Knowledge analysis means understanding domain knowledge in a context which is situated in community contexts. The contextual knowledge analysis is performed to explore different community situations where domain knowledge is created, disseminated and utilized. The approach to contextual knowledge analysis is a differentiation between creation, dissemination and utilization of knowledge. The CommonKADS modeled the organic rice planting domain knowledge in this study into three corresponding parts, task knowledge, inference knowledge and domain knowledge. The three main parts are linked to task knowledge which describes the knowledge-intensive tasks of the organic rice growing, inference knowledge which describes using knowledge to carry out the reasoning process and domain knowledge which refers to knowledge of human experts based on their experiences. The domain knowledge was validated and taught back from experts.

\subsection{Ontology Development: Stage 4}

This step of the methodology developed additional social science ontologies and knowledge model using CommonKADS. The CommonKADS model has a variety of components such as the organization model, task model, agent model, knowledge model, communication model and design model. This research identified jargons which are experts' vocabulary in their domain knowledge and then the ontology knowledge creation to develop the organic rice farming ontology knowledge based on four main social science ontologies derived from the biology, chemistry, physics and mathematics concepts of Thai's curriculum in lower secondary school.

\subsection{Learning Process Technique: Stage 5}

This study proposes a learning process technique of an effective tutorial ontology modeling on organic rice farming for non-science and technology educated farmers using knowledge engineering. This stage shows how to transfer appropriate technology effectively for non-science and technology educated farmers via a tutorial ontology. 


\section{Research Finding}

\subsection{Sample Selection}

A case study of this research is Phrao District, Chiang Mai Province in the northern part of Thailand where there is organic rice farming community. People in this case study are 36,393 people approximately (The National Statistical Office of Thailand, 2014) and most of people are farmers. This study focuses on an adaptive organic rice-farming group as a learning process technique study sample test because this group represents a research problem. There are 10 adaptive organic rice farmers who are non-science and technology educated people as study samples. These adaptive organic rice farmer samples were divided equally into two groups, i.e., control group and experimental group. The requirement knowledge and appropriate technology to renew case study community will be validated by non-structure interview from stakeholders and bio data analysis of case study.

\subsection{Learning Process Technique}

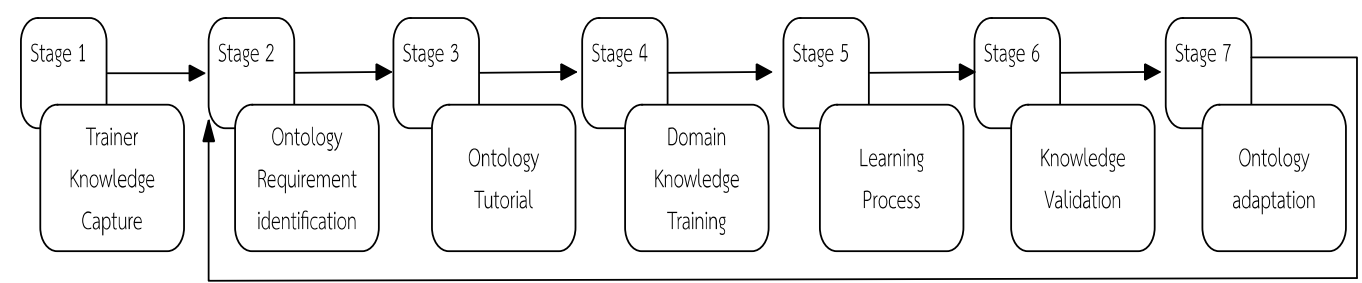

Figure 2. The learning process technique framework for non-science and technology educated farmers using knowledge engineering

This effective tutorial ontology modeling on organic rice farming for non-science and technology educated farmers as learning process technique was proposed to transfer appropriate technology effectively and close gap between expert and non-science and technology educated farmers (shown in Figure 2). There are 7 stages of learning process technique which are stage 1: trainer knowledge capture, stage 2: ontology requirement identification, stage 3: ontology tutorial, stage 4: domain knowledge training, stage 5: learning process, stage 6: knowledge validation and stage 7: ontology adaptation. This knowledge transfer technique of any appropriate technology from sustainable development project can be generalized for non-science and technology educated people.

\subsection{Trainer Knowledge Capture: Stage 1}

After following stage one methodology, the knowledge model was created from the task, inference, domain template and ontology of CommonKADS (as shown in Figure 3). The results follow the domain concepts of the organic rice planting as the appropriate technological knowledge from sustainable development projects. Both tacit knowledge and explicit knowledge: repositories, portal link, etc., were collected and used as knowledge support. The term of expert's domain knowledge refers to knowledge which is specific for a given domain of practice, both in terms of more abstract knowledge and domain knowledge embedded in the organizational, social and material context of a given practice. This research has nine tasks of organic rice planting knowledge: T1-soil analysis, T2-seed selection, T3-rice seedling, T4-soil preparation, T5-organic rice growing, T6-water management, T7-rice disease, pet, insect protection, T8-harvest and T9- soil development (shown in Figure 4). Each of 9 tasks was modeled into task, inference, domain knowledge from organic rice farming trainer. 


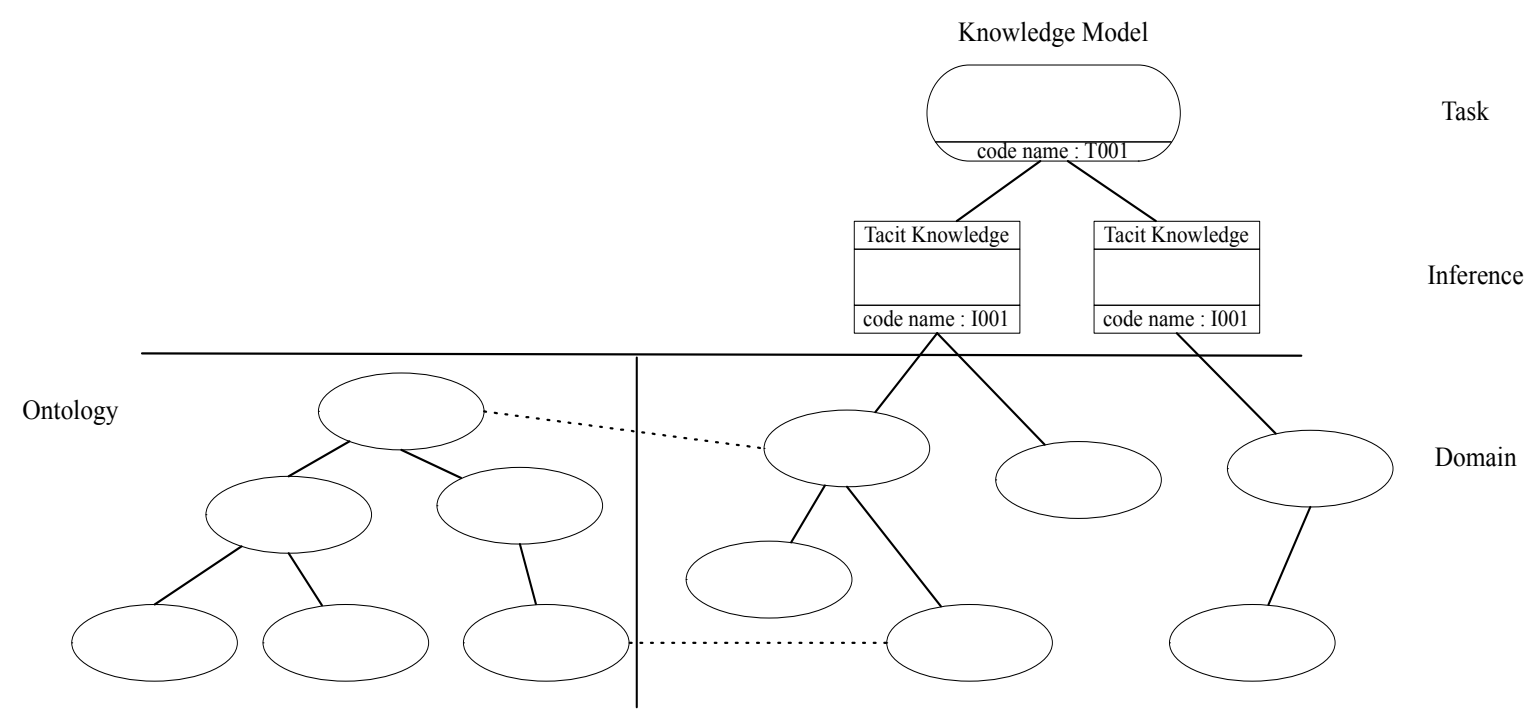

Figure 3. The knowledge modelling template of CommonKADS

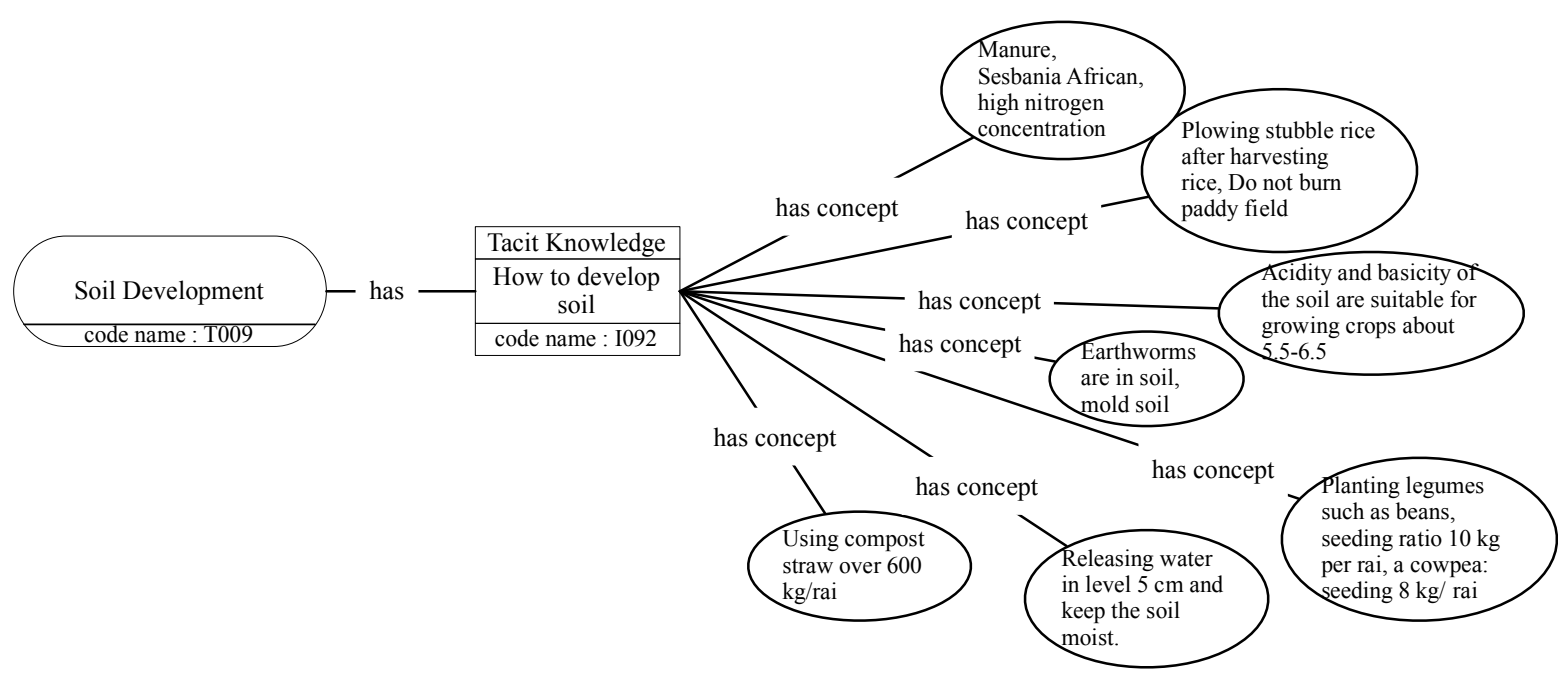

Figure 4. The knowledge capture of T9-soil analysis task of organic rice planting knowledge 
4.4 Social Science Ontologies Identification and Development Based on Thai's Curriculum of Lower Secondary School (Muttayom 1-3): Stage 2
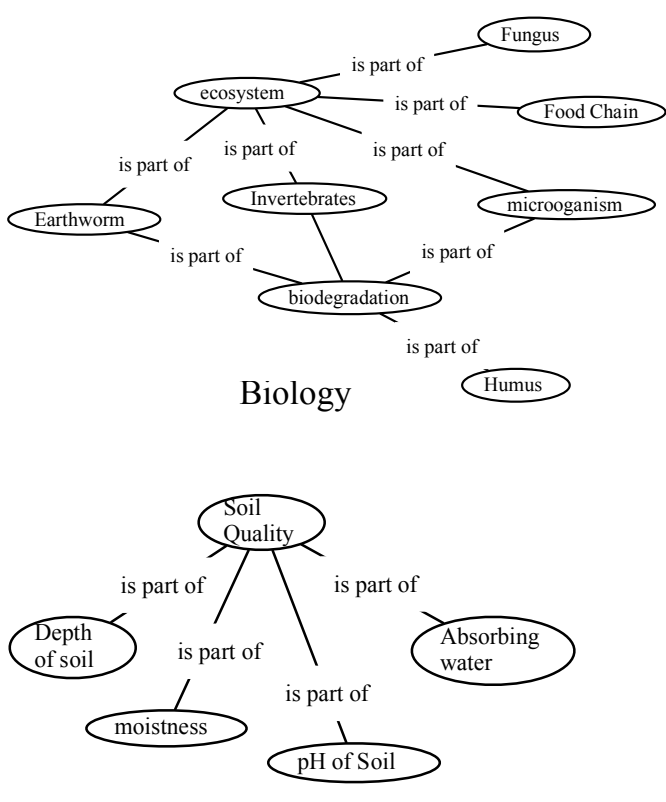

Physics
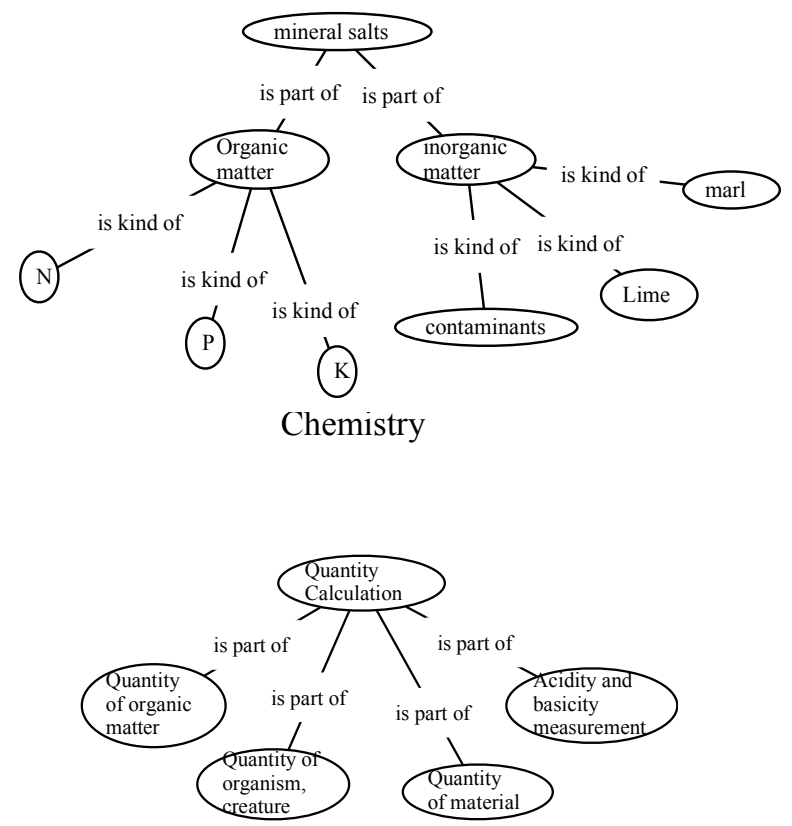

Math

Figure 5. Social science ontologies in four concepts of biology, chemistry, physic and math based on Thai's curriculum of lower secondary school

After tacit knowledge of organic rice farming trainer was captured using knowledge engineering. This ontology identification and development step focuses on jargons, which are experts' vocabulary in their domain knowledge and then the social science ontology knowledge developed the organic rice farming ontology knowledge related to jargons of experts and based on four main social science ontologies derived from the biology, chemistry, physics and mathematics concepts of Thai's curriculum in lower secondary school. It can be seen in Figure 5 some examples of social science ontology in biology, chemistry, physic and math. This study identified and developed the first version of social science ontology into 92 ontologies, which were specification of conceptualization on organic rice farming. All social science ontologies provided for non-science and technology educated farmers to common understanding of organic rice trainer effectively, so that the adaptive organic rice farmers as experimental group in this study can apply and reuse their own ontology, domain knowledge and create their new domain knowledge.

\subsection{Ontology Tutorial for Samples: Stage 3}

The samples of this research were divided into a control group and experimental group which each group had five adaptive organic rice farmers equally to approve effective ontology tutorial on organic rice farming. The five adaptive organic rice farmers in experimental group were tutored social science ontology on organic rice farming before all sample groups will be trained by organic rice trainers. The control group was used as blank to prove ontology effectiveness.

\subsection{Domain Knowledge Training: Stage 4}

Both control group and experimental group were trained organic rice farming domain knowledge by trainers expertize in nine tasks of organic rice farming. Trainers designed a training course and activities which involved all tasks of organic rice knowledge as appropriate technology for both groups.

\subsection{Learning Process: Stage 5}

The control and experimental groups were trained on organic rice farming by trainers and were tested knowledge gained from trainers following Bloom's taxonomy framework. It can be seen from Figure 6 that there were numbers of $\mathrm{n}$ domain knowledge which disseminate to both sample groups. The experimental group was trained 
number of $m$ social science ontologies on organic rice farming first version.

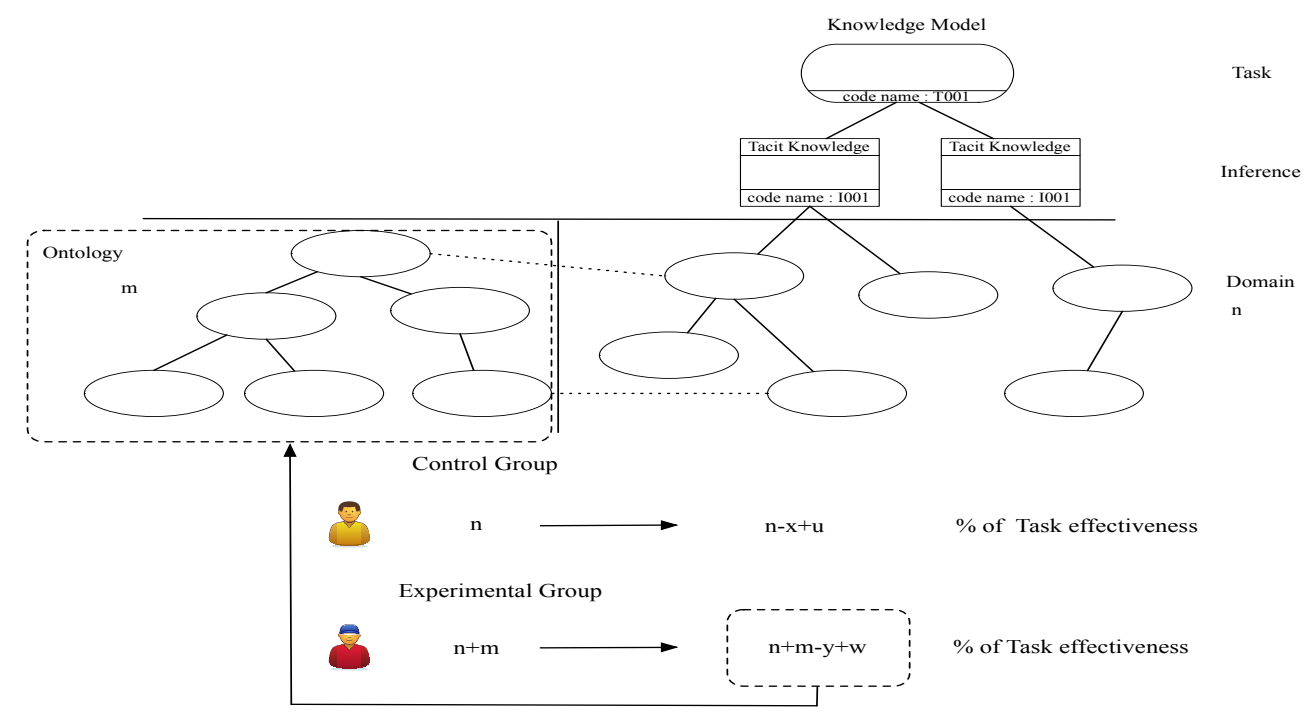

Figure 6. A learning process on organic rice farming knowledge from both control and experimental groups $(\mathrm{n}=$ number of domain knowledge, $\mathrm{m}=$ number of ontology, $\mathrm{x} ; \mathrm{y}=$ lost domain knowledge, $\mathrm{u} ; \mathrm{w}=$ new domain knowledge of adaptive organic rice farmers)

An ontology mapping is a set of expressions that has a different ontology, which was mapped in this stage. The domain knowledge of both control and experimental group were elicited and captured via interview using CommonKADS to map learning outcome comparing between one by one of each control group and experimental group following Bloom's taxonomy framework (shown in Figure 7). 


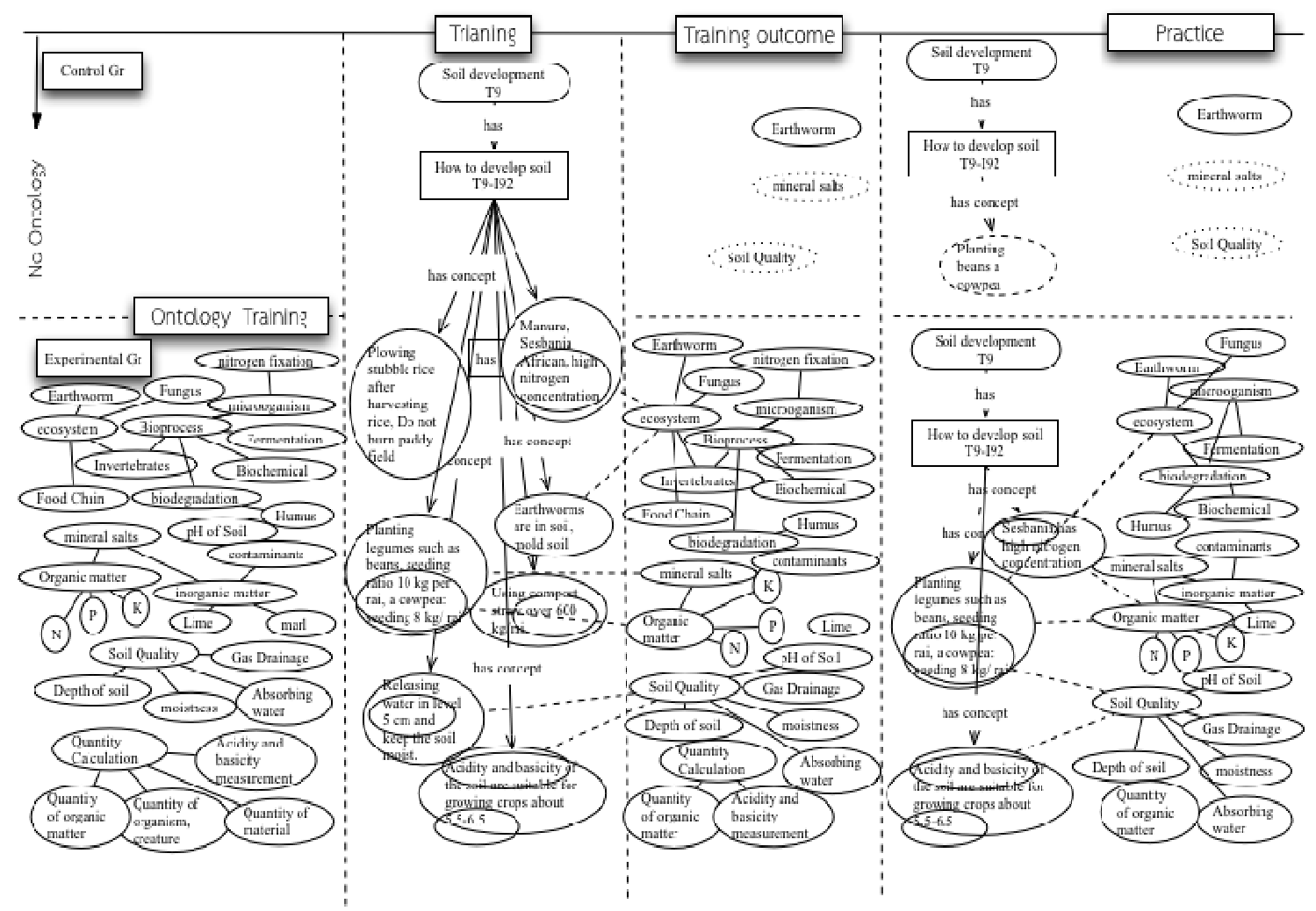

Figure 7. The domain knowledge validation of organic rice farming knowledge from both control and experimental groups

The experimental group had tutorial social science ontology on organic rice farming as it can be seen in mapping in Figure 7. The farmers in this group could remember and reason ontologies to understand expert's concept and create their own domain knowledge which was appropriate to their community.

\subsection{Ontology Knowledge Validation: Stage 6}

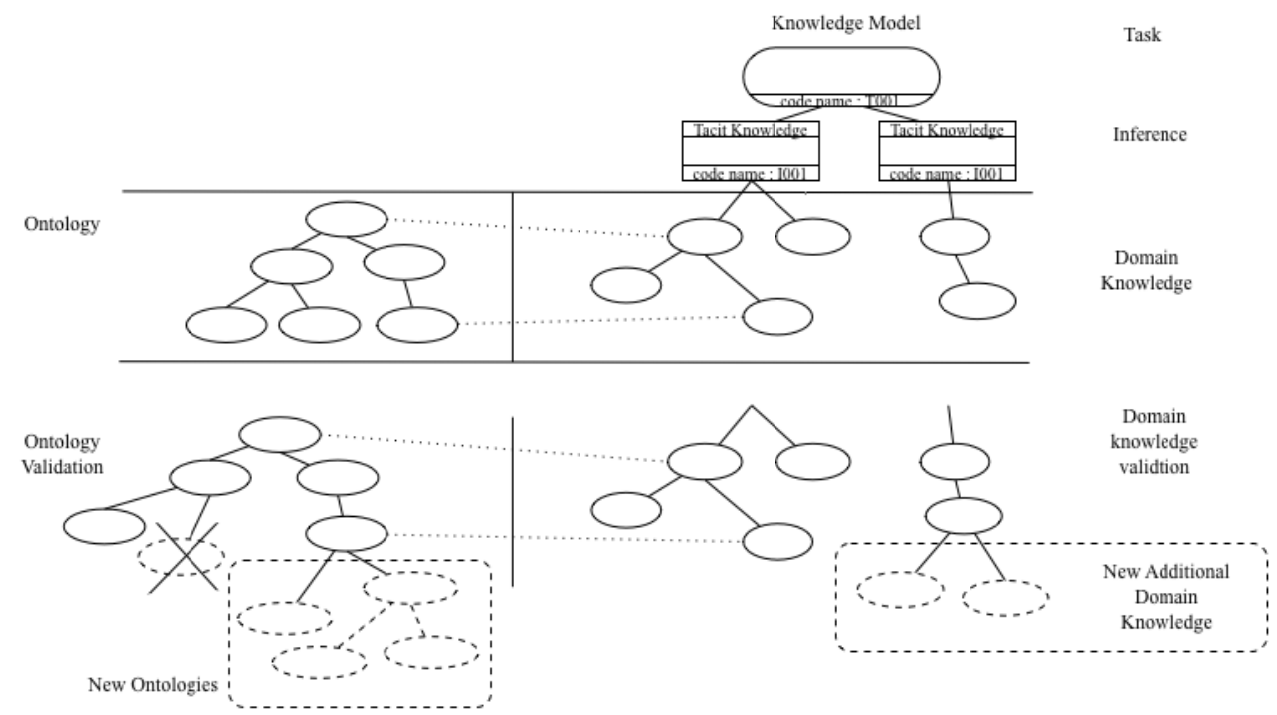

Figure 8. The domain knowledge validation of organic rice farming knowledge from both control and experimental groups 
The tutorial social science ontology on organic rice farming was validated via a count of number of using domain knowledge to organic rice farming effectively from both control and experimental groups (shown in Figure 8). Some ontologies cannot be used on organic rice appropriately, and some ontologies of their samples can be created and reasoned which was related to expert's domain knowledge to use for organic rice farming. In addition, the new domain knowledge on organic rice farming which is appropriate to a case study community was created by non-science and technology educated farmers in experimental group.

\subsection{Ontology Adaptation: Stage 7}

The social science ontologies of first version were minimized in this stage and improved ontology into appropriate social science ontology for non-science and technology educated farmers on organic rice farming to understand experts. Consequently, the minimized and appropriate social science ontology on organic rice farming in this stage will be returned to Stage 2 in order to identify and develop a second version which is refined in an effective tutorial ontology version for non-science and technology educated farmers.

\subsection{Effectiveness of Tutorial Social Science Ontology in Learning Process}

The results of social science ontology effectiveness in learning process show that the experimental group which is with ontology training can understand and practise knowledge from experts more than the control group which is without tutorial social science ontologies (shown in Table 1). The average throughput of organic rice farming domain knowledge in learning process was counted and validated in terms of practising domain knowledge, appropriate domain knowledge with their community and acquiring knowledge by themselves in both control and experimental groups.

Table 1. The comparison of an average throughput of domain knowledge between control and experimental groups

\begin{tabular}{lcccc}
\hline \multirow{2}{*}{$\begin{array}{l}\text { Terms of using } \\
\text { domain knowledge }\end{array}$} & $\begin{array}{c}\text { Number of } \\
\text { domain } \\
\text { knowledge }\end{array}$ & $\begin{array}{c}\text { Percentage of number } \\
\text { of domain knowledge }\end{array}$ & $\begin{array}{c}\text { Number of } \\
\text { domain } \\
\text { knowledge }\end{array}$ & $\begin{array}{c}\text { Percentage of number } \\
\text { of domain knowledge }\end{array}$ \\
\hline $\begin{array}{l}\text { Practising domain } \\
\text { knowledge }\end{array}$ & 19.2 & 12.97 & 53.40 & 36.08 \\
\hline $\begin{array}{l}\text { Appropriate domain } \\
\text { knowledge }\end{array}$ & 11 & 7.43 & 26.2 & 17.57 \\
\hline $\begin{array}{l}\text { Acquiring domain } \\
\text { knowledge }\end{array}$ & - & - & 8.2 & 5.54 \\
\hline
\end{tabular}

The total number of organic rice farming domain knowledge from experts was 148 domain knowledge to train in learning process for both control and experimental sample groups, then the output of domain knowledge of learning process learned by both sample groups was counted and calculated as percentage (shown in Figure 9). 


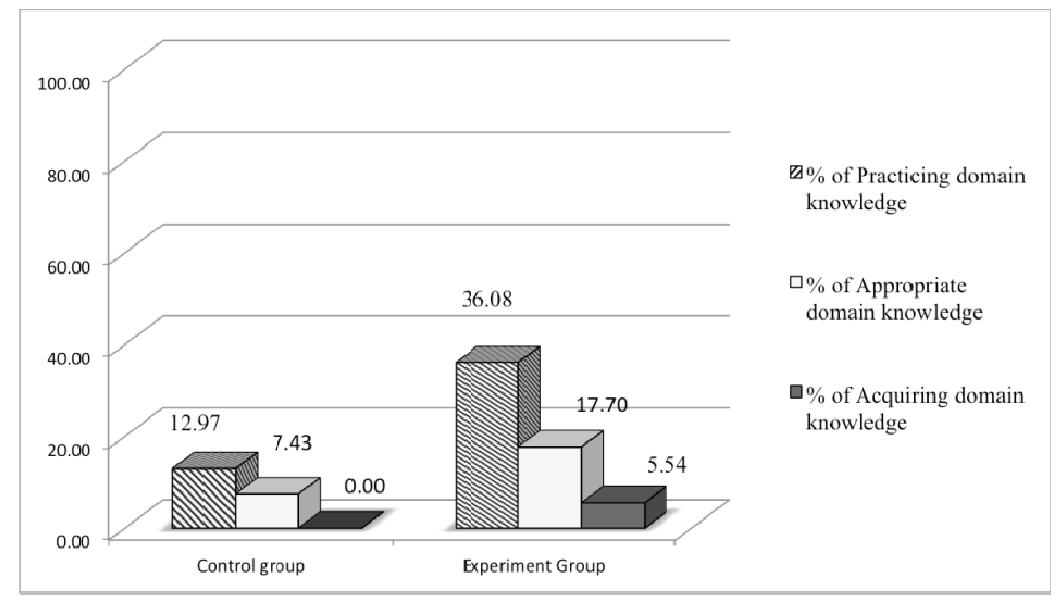

Figure 9. The average throughput of organic rice farming domain knowledge comparing between control and experimental sample group

\section{Discussion and Conclusion}

This research aims to propose effective tutorial social science ontologies on organic rice farming as an appropriate technology based on sustainable development projects for non-science and technology educated farmers using knowledge engineering approach. Organic rice farming domain knowledge will be captured, analyzed and structured from experts using CommonKADS and the social science ontology on organic rice farming will be identified and developed based on lower secondary school of Thai curriculum which provides biology, chemistry, math and physics concepts.

The effective tutorial ontology model focuses on social science and technology ontologies based on Thai's curriculum of lower secondary school in order to effectively represent knowledge of the organic rice farming. This study has been mainly concerned with capturing and representing knowledge found in the logic and structure of the organic rice farming knowledge through effective tutorial ontology. This research aims at capturing domain knowledge in a generic way and a commonly agreed understanding of domain which can be shared, reused and operationalized across communities. The effective social science ontologies contain the conceptualization within the biology, chemistry, math and physic concepts and the relations between them. This study has developed ontology, enabled annotation using knowledge engineering with a perspective on provision of a knowledge scenario. In this paper, ontologies provide a means for modelling of the relevant organic rice farming knowledge.

Although ontologies can be advantageous in numerous ways, this study emphasized the benefits of ontologies in supporting knowledge for non-science and technology educated farmers. The resulting knowledge package should relate the basic entities defined in the ontologies with text and images, which support enhanced understanding of the ontology construction. The adaptive organic rice farmers in Phrao District, Chiang Mai Province as knowledge workers could also use the additional social science ontologies to develop this work as a vocational tool to improve their competency and disseminate knowledge to people in rural areas in order to develop their community.

The most important role of tutorial ontology is to enable and to enhance knowledge sharing and reusing which the ontology closes knowledge gap among experts and non-science and technology educated farmers. This study has focused on ontology creation by using a CommonKADS methodology, which provides tools to support structuring knowledge. The effective social science ontology on organic rice knowledge between the organic rice farmers will solve the problem of knowledge loss and misunderstanding between different local areas. Non-science and technology educated farmers can learn from this domain knowledge structure by reasoning ontology to improve and develop their communities.

\section{References}

Akehurst, G., Rueda-Armengot, C., Lopez, S. V., \& Marques, D. P. (2011). Ontological Supports of Knowledge: Knowledge Creation and Analytical Knowledge. Management Decision, 49(2), 183-194. http://dx.doi.org/10.1108/00251741111109106

Angele, J., Fensel, D., Landes, D., \& Studer, R. (1998). Developing knowledge based systems with MIKE. 
Journal of Automated Software Engineering, 5(4), 389-418. http://dx.doi.org/10.1023/A:1008653328901

Anumba, C. J., Issa, R. A., Pan, J., \& Mutis, I. (2008). Ontology-based information and knowledge management in construction. International Journal of Construction Innovation, 8(3), 218-239. http://dx.doi.org/10.1108/14714170810888976

Chou, T. H., Vassarand, J. A., \& Lin, B. (2008). Knowledge management via ontology development in $\begin{array}{lllll}\text { accounting. International Journal of } & \text { Kybernetes, } & 37(1), & 36-48 .\end{array}$ http://dx.doi.org/10.1108/03684920810850970

CSIR Built Environment Unit. (2008). Appropriate Technologies in the Water Sector in South Africa, May.

Gennari, J. H., Musen, M. A., Fergerson, R. W., Grosso, W. E., Crubezy, M., Eriksson, H., . . Tu, S. W. (2003). The evolution of protege: An environment for knowledge-based systems development. International Journal of Human Computer, 58(1), 89-123. http://dx.doi.org/10.1016/S1071-5819(02)00127-1

Gil, R. J., \& Martin-Bautista, M. J. (2012). A novel integrated knowledge support system based on ontology learning: Model specification and a case study. Knowledge-Based Systems, 36, 340-352. http://dx.doi.org/10.1016/j.knosys.2012.07.007

Isotani, S., \& Mizoguchi, R. (2008). An Ontology-based Framework and its Application to Effective Collaboration. Clei Electronic Journal, 11(1), 1-9.

Martine, C. (1999). Methodology and tools oriented to knowledge engineering applications, MOKA public report No. 2. Retrieved from http://www.kbe.conventry.ac.uk/MOKA

Ministry of Education, Thailand. (2008). The Basic Education Core Curriculum B.E. 2551 (A.D.2008), July 11.

Office of the Permanent Secretary. (1999). Ministry of Education, Statistic Report.

Ruanglertboon, F. (2003). The higher education philosophy of his majesty the king Bhumibol Adulyadej (A dissertation submitted in partial fulfilment of requirements of the degree of doctor of philosophy in higher education, Department of higher education, faculty of education, Chulalongkorn university).

Saito, A., Umemoto, K., \& Ikeda, M. (2007). A strategy-based ontology of knowledge management technologies. Journal of Knowledge Management, 11(1), 97-114. http://dx.doi.org/10.1108/13673270710728268

Schreiber, A. Th., Akkermans, J., Anjewierden, A., de Hoog, R., Shadbolt, N., van de Velde, W., \& Wielinga, B. (2000). Knowledge engineering and management: The CommonKADS methodology. MIT Press.

The National Statistical Office of Thailand, Chiang Mai Province. (2014, October). Retrieved from http://chiangmai.nso.go.th

Uschold, M., \& Gruninger, M. (1996). Ontologies: Principles, Methods and Applications. Knowledge Engineering Review, 11(2), 93-115. http://dx.doi.org/10.1017/S0269888900007797

\section{Copyrights}

Copyright for this article is retained by the author(s), with first publication rights granted to the journal.

This is an open-access article distributed under the terms and conditions of the Creative Commons Attribution license (http://creativecommons.org/licenses/by/3.0/). 